\title{
Construction and functional analysis of luciferase reporter plasmid containing connexin43 gene promoter
}

\author{
Hui Li, Jiapeng Li, Weilin Shi, Xiaoyu Zhang, Yuan Xiang, Xinghua Liao and Tongcun Zhang ${ }^{a}$ \\ Institute of Biology and Medicine, Wuhan University of Science and Technology, Hubei, China
}

\begin{abstract}
Connexin 43 (Cx43), the principal gap junction protein in vascular smooth muscle cells(VSMCs) resulting in modulation of gap junction. Myocardin is thought to have a key role in Vascular Smooth Muscle Cell (VSMC) development by acting on CArG-dependent genes. In this study, a human $\mathrm{Cx} 43$ promoter luciferase reporter construct was generated by PCR amplification of $\mathrm{Cx} 43$ promoter. The PCR fragment was digested and cloned into pGL3-Basic vector. The promoter sequence was verified by sequencing. The results showed that luciferase reporter plasmids of $\mathrm{Cx} 43$ promoter were successfully constructed. Then the effects of a key transcription factor, which plays important roles in $\mathrm{Cx} 43$ levels control, were investigated by luciferase reporter assays in HEK293. The results showed that myocardin can enhance transcriptional activity of $\mathrm{Cx} 43$. Our observations provide evidence that Myocardin targets Cx43 expression directly.
\end{abstract}

\section{Introduction}

Gap junctions mediate cell communication by allowing the passage of molecules from one cell to another. The major role of gap junction intercellular communication (GJIC) is considered to be the maintenance of homeostasis in organisms[1]. Connexin $43(\mathrm{Cx} 43)$, the principal gap junction protein in vascular smooth muscle cells(VSMCs), regulates movement of ions and other signaling molecules through gap junction intercellular communication (GJIC) and plays important roles in maintaining normal vessel function; however, many of the signaling mechanisms controlling Cx43 in VSMCs are not clearly described, it has been identified as a potential drug target for the treatment of a broad range of diseases [2]. Cell-to-cell transfer of small molecules through gap junctions regulates diverse biologic processes[3, 4]. Moreover, the decreased connexin 43 mRNA is correlated with its protein levels[5]. As the biologic effects that occur downstream of messages communicated by gap junctions expand, it becomes imperative to be able to develop assays to define the biologically relevant second messengers that are passed between cells. Recently, a large number of studies have implicated connexin 43 (Cx43)containing gap junctions in a complex array of biologic responses that influence bone quality in vivo[6-9].

\footnotetext{
${ }^{a}$ Xinghua Liao and Tongcun Zhang (zhangtongcun@wust.edu.cn) are Corresponding author. This work was financially supported by National Natural Science Foundation of China (No. 31501149, $31401117,31471282,31440038,31270837)$. The science and technology young training program of the Wuhan University of Science and Technology (2016)(2016xz035).
} 
Myocardin, a coactivator of serum response factor (SRF), is highly expressed in embryonic cardiac and smooth muscle lineages plays a critical role in regulating smooth muscle cells phenotype switch $[10,11]$. Myocardin belongs to the SAP (SAF-A/B, Acinus, and PIAS) domain family of transcription factors and is a cardiac and smooth muscle-specific expressed transcriptional coactivator of serum response factor (SRF) which binds to the $\mathrm{CArG}$ box $(\mathrm{CC}[\mathrm{A} / \mathrm{T}] 6 \mathrm{GG})$ to regulate cardiac and smooth muscle-specific genes [12].

In this study, Cx43 promoter was amplificated from human genome by PCR and inserted into pGL3 (luciferase vector) basic vector successfully. Furthermore, luciferase assays were performed in HEK293. The results showed that myocardin activates $\mathrm{Cx} 43$ promoter transcription. Point-mutagenesis studies showed that one $\mathrm{CArG}$ box site was required for $\mathrm{Cx} 43$ activation by Myocardin. Our observations provide evidence that Myocardin targets Cx43 expression directly. Our research will help us to screen interaction between two Genes.

\section{Materials and methods}

\subsection{Cell Culture}

Human embryonic kidney (HEK)293 cells line was obtained from American Type Culture Collection. VSMCs were grown in Dulbecco's modified Eagle's medium (DMEM) (GIBCO) supplemented with $10 \%$ fetal bovine serum (FBS) at $37^{\circ} \mathrm{C}$ in a $5 \% \mathrm{CO}_{2}$ incubator. Cell were plated in 24-well plates, cultured to $60 \%-80 \%$ confluence and transfected with PEI[13] as previously described.

\subsection{Plasmid Construction}

The fragments of $\mathrm{Cx} 43$ promoter region were generated by PCR using human genomic DNA as a template and subcloned into the KpnI and NheI sites of pGL3-Basic vector. The human genome was extracted from HEK293 cells line. Cx43 promoter fragment from -643 to +103 is amplified by PCR using the primers (F: 5'- CGGGGTACCTGAAAGATGGATTGGGTAT -3'; R: 5'TGTGCTAGCGAACTCCTTGGAGGATGA -3'). CX43-truncated promoter fragment from -486 to +103 is amplified by PCR using the primers (F: 5'CGGGGTACCCACTCACACCTACCTCTAACTTCAC $\quad-3^{\prime} ; \quad$ R: 5'CGCGCTAGCTTGgaggatgaAgtAaAATGAAAAG -3')( Figure 1). PCR condition is as follows: Pre-degeneration for $5 \mathrm{~min}$ at $94^{\circ} \mathrm{C}$, denaturation for 30 seconds at $94^{\circ} \mathrm{C}$, annealing for 30 second at $58^{\circ} \mathrm{C}$, and extension for $1 \mathrm{~min}$ at $72^{\circ} \mathrm{C}$. PCR reaction was carried out for 32 cycles and PCR products were visualized in $1 \%$ agarose gels stained with ethidium bromide under UV transillumination.

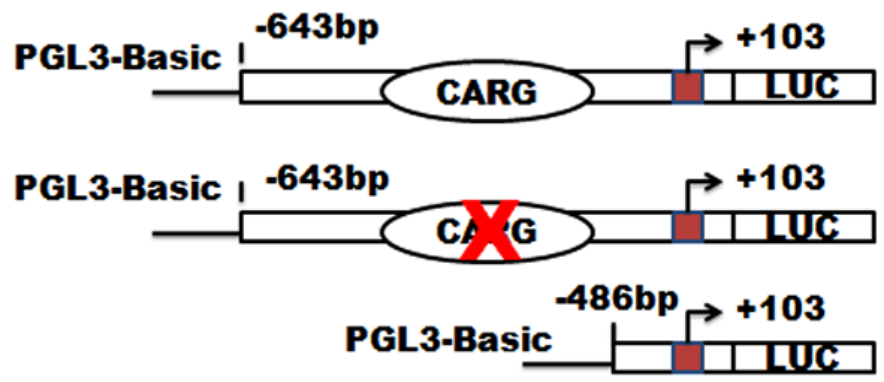

Figure 1. Sequential deletions and mutations of the human $\mathrm{Cx} 43$ promoter were fused to a luciferase reporter. HEK293cells in 24-well plates were co-transfected with the Myocardin expression plasmid $(1 \mu \mathrm{g} / \mathrm{well})$ and various wild-type. 
The PCR product and pGL3-Basic vehicle plasmid were digested with restriction enzyme KpnI and NheI at $37^{\circ} \mathrm{C}$ for $2 \mathrm{~h}$. The fragment of PCR product and pGL3-Basic vehicle plasmid were mixed with $1 \mu \mathrm{L}$ T4 ligase buffer and $1 \mu \mathrm{L}$ T4 DNA ligase and added water to $10 \mu \mathrm{L}$, incubated at $16^{\circ} \mathrm{C}$ for $2 \mathrm{~h}$, and then transformed into competent E.coli. Monoclonal colony was well separated by incubating in $3 \mathrm{~mL} \mathrm{LB}$ which contains ampicillin at $37^{\circ} \mathrm{C} 16$ hour. A monoclonal colony was picked and cultured in LB. Cx43 promoter point mutants were made with the TransStart FastPfu DNA Polymerase kit(TransGen) using Cx43 promoter(-634 to +103) as a template by the following primers: (F: 5'TTAATTGTCCTTGCTTACAAAATTTTTAAGGGAATTAGATCAT $\quad$-3'; R: $\quad$ 5'ATGATCTAATTCCCTTAAAAATTTTGTAAGCAAGGACAATTAA -3'). The plasmid was extracted and all constructs including mutants were verified by DNA sequencing.

\subsection{Luciferase reporter assays}

300ng of Cx43 promoter reporter, Myocardin (Myocardin-pCDNA3.1) expression plasmid as indicated were cotransfected. Cells were incubated for $24 \mathrm{~h}$ before harvest. $50 \mu \mathrm{L}$ of protein extracts $(100$ $\mu \mathrm{L} /$ well) were prepared for luciferase assays, which were measured by using a luciferase reporter assay system (Promega) on a Synergy ${ }^{\mathrm{TM}} 4$ (Bioteck). Transfer $50 \mu \mathrm{L}$ of each lysate into the wells of an opaque 96-well assay plate. Add $100 \mu \mathrm{L}$ per well luciferase lysis buffer. Incubate at room temperature for $2 \mathrm{~min}$ with gentle shaking. All experiments were performed at least three times with different preparations of plasmids and primary cells, producing qualitatively similar results. Relative luciferase activity can be determined by dividing the firefly luciferase activity by the renilla luciferase activity. Next, average the replicates together and graph the data.

\section{Result}

\subsection{Construction of Cx43 promoter luciferase reporter plasmid}

To estimate the PCR amplification of $\mathrm{Cx} 43$ promoter, agarose gel electrophoresis was performed. As shown in Figure 2, a single band emerged at the site of $746 \mathrm{bp}$, which represents the PCR products of Cx43 promoter.

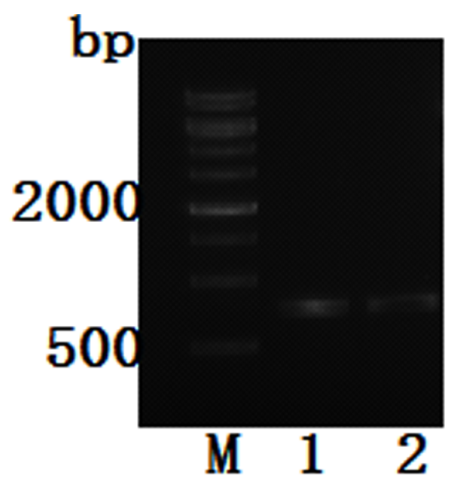

Figure 2. Agarose gel electrophoretic analysis of PCR product.

1-2: $\mathrm{Cx} 43$ gene promoter.

Then, the PCR product was digested by double restriction enzymes and cloned to the pGL3-Basic vector. After that, the recombinant plasmid was extracted and purified, and the agarose gel electrophoretic analysis was performed. Figure 3 showed the size of recombinant plasmid that was purified. 


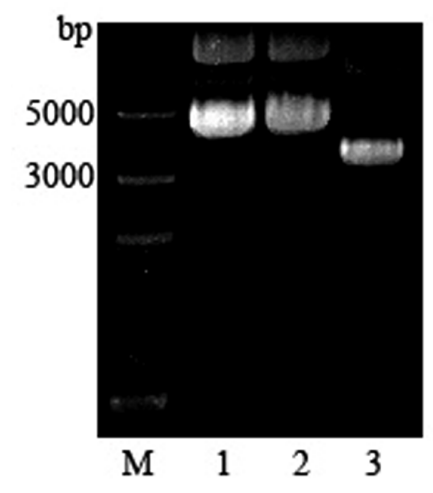

Figure 3. Agarose gel electrophoretic analysis of plasmids. 1-2: recombinant plasmid 3: pGL3-Basic vehicle plasmid.

To confirm the recombinant plasmids, we used double restriction enzymes to digest them and then electrophoresed through agarose gel. As shown in Figure 4, the recombinant plasmid was cut into two bands. One band was at about $74 \mathrm{bp}$, which represents $\mathrm{Cx} 43$ promoter, and another band was at 5,000 $\mathrm{bp}$, which represents pGL3-Basic vehicle plasmid. The luciferase reporter plasmid of Cx43 gene promoter was further confirmed by sequencing. The result of DNA sequence alignment showed that luciferase reporter plasmid containing $\mathrm{Cx} 43$ promoter was constructed successfully.

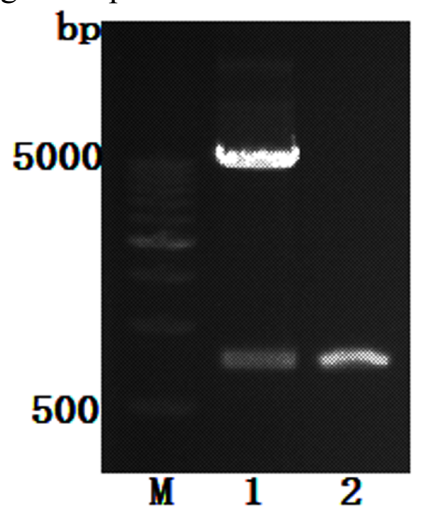

Figure 4. Agarose gel electrophoretic analysis of plasmids. 1: recombinant plasmid; 2: CX43 gene promoter.

\subsection{Fluorescence of the efficiency of transduction}

The transfection efficiency was demonstrated using a EGFP (enhanced green fluoresent protein) expression plasmid. As shown in Figure 5, the transfection efficiency was approximately $60 \%$, demonstrating that DNA was transfected efficiently into HEK293. 


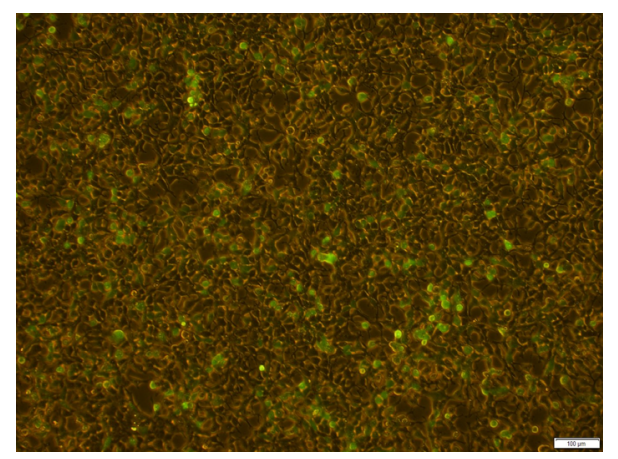

Figure 5. The transfection efficiency of HEK293.

\subsection{Myocardin can enhance the transcriptional activity of Cx43 promoter obviously}

Luciferase Reporter Assays were performed after HEK293 were transfected with myocardin and Cx43 promoter. Contrasting with control group transfected with pcDNA3.1, myocardin showed a significant effect to enhance the transcription activity of $\mathrm{Cx} 43$ promoter (Figure 6a). Our data have demonstrated that Myocardin is able to stimulate $\mathrm{Cx} 43$ promoter activity, and then we asked whether CArG box site region within $\mathrm{Cx} 43$ promoter is responsible for Myocardin activation. $\mathrm{Cx} 43$ luciferase reporter constructs driven by $\mathrm{Cx} 43$-truncated promoter region and $\mathrm{Cx} 43$-mutant promoter region were generated(Figure 6b,6c). Transient transfection assays were performed. $\mathrm{Cx} 43$ promoter construct plasmid was cotransfected with increasing amounts of Myocardin expression plasmid. As shown in Figure 5, Cx43 promoter reporter activationby Myocardin was detected when as low as 250ng of Myocardin was transfected. Increasing amounts of Myocardin not led to higher expression of Cx43 promoter reporter. Transfection of 250ng Myocardin expression plasmid resulted in up to 170 fold activation of $\mathrm{Cx} 43$ promoter reporter. This indicated that Myocardin activates $\mathrm{Cx} 43$ gene expression transcriptionally.

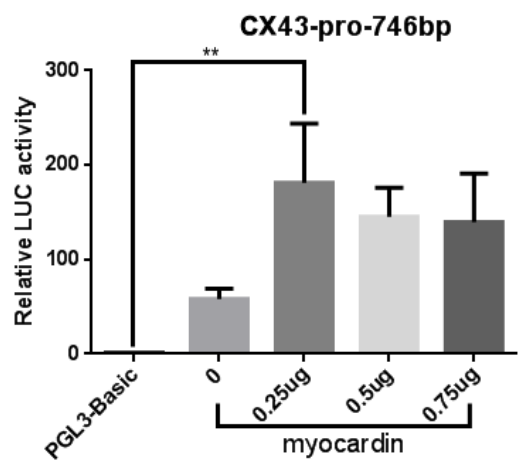

Figure 6a. Myocardin can enhance the transcriptional activity of $\mathrm{Cx} 43$ (fold). 


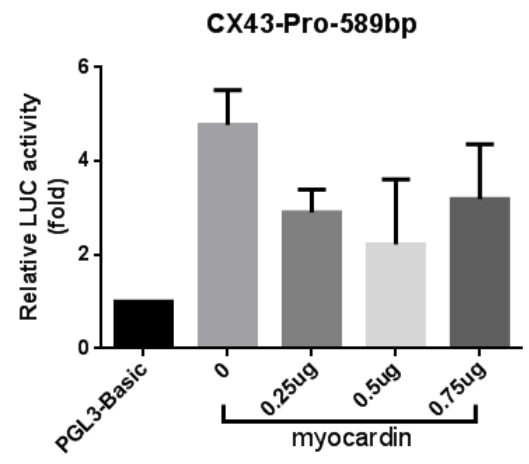

Figure 6b. Myocardin can not enhance the transcriptional activity of $\mathrm{Cx} 43$ - truncated.

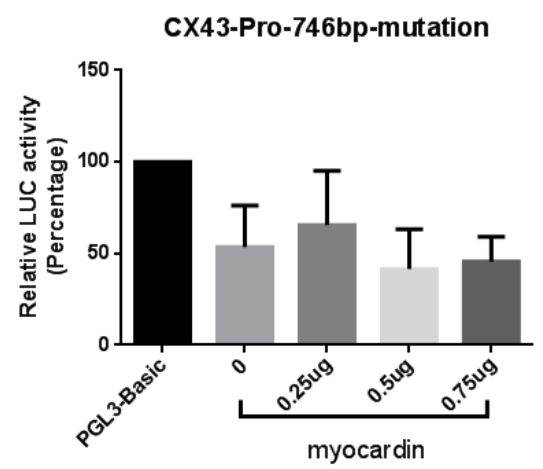

Figure 6c. Myocardin can not enhance the transcriptional activity of CX43-mutant.

\section{Discussion}

Gap junctions consist of channels between neighboring cells, mediating transfer of chemical molecules or electrical stimulation[14-15]. In some vascular smooth muscle diseases, Cx43 up-regulation and coupling of smooth muscle occurred, thereby inducing change in contractile property through upregulation of cell-cell communication[16-18].

In natural development, Myocardin expression level was maintained over threshold level; thus, Myocardin would not induce significant changes in Cx43 expression. The other novel finding here is a new role for Myocardin as a repressor of $\mathrm{Cx} 43$ in smooth muscle. Myocardin has been known as a key regulator for VSMC and cardiac contractile genes but its regulation of non-contractile genes is less clear.Interestingly, there are conflicting data over the role of Cx43 in VSMC with one report showing an effect on Myocardin-dependent growth[19] .Myocardin was originally identified as a serum response factor (SRF) co-factor expressed only in cardiomyocytes and smooth muscle cells [20]. Myocardin increases activation of SRF-dependent genes by forming a higher order complex with SRF and facilitating its association with its CArG box DNA binding domain. Transcriptional activation is promoted by a variety of mechanisms including myocardin's own powerful transcriptional activation domain [21].

In this study, we cloned Cx43 promoter luciferase reporter plasmid successfully and found that myocardin could enhance the transcriptional activity of $\mathrm{Cx} 43$ promoter. Our findings support the premise from the transcriptional level that myocardin can increase the ability of $\mathrm{Cx} 43$ degradation in HEK293. Our observations provide evidence that Myocardin targets Cx43 expression directly. Our research will help us to screen interaction between two Genes. Research in the next decade should be focused on the development of new reagents and animal models to further understand this remarkable 
cofactor's functionin normal and pathological processes. In addition, there should be effort devoted towards fully elucidating transcriptomes under control of Myocardin, particularly the expanding class of long non-coding RNAs. Further, we need to define the mechanisms through which Myocardin functions independently of SRF.

\section{References}

1. A.C.Sharrow, Y.Li, A.Micsenyi, R.D.Griswold, A.Wells, S.S.Monga, H.C.Blair. Exp. Cell Res.314, 297-308. (2008).

2. C.N.Joshi, D.N.Martin, P.Shaver, C.Madamanchi, B.J.Muller-Borer, D.A. Tulis . Front Physiol. Jun 21;3:220. (2012).

3. M.Vinken. Cell Mol Life Sci.Aug;72(15):2775-8. (2015).

4. M.S.Nielsen, L.N.Axelsen, P.L.Sorgen, V.Verma, M.Delmar, N.H.Holstein-Rathlou.Compr. Physiol 2(3):1981-2035(2012).

5. K.Cesen-Cummings, M. J.Fernstrom, A. M.Malkinson, and R. J.Ruch. Carcinogenesis (Lond.),19:61- 67. ( 1998).

6. L.I.Plotkin. 2014 Apr 4;5:131. (2014).

7. S.A.Lloyd, A.E. Loiselle, Y Zhang, H.J.Donahue. J Bone Miner Res 29:275-286(2014).

8. A.M.Buo, J.P.Stains. FEBS Lett 588:1315-1321(2014).

9. J.P.Stains,M.P.Watkins,S.K.Grimston,C.Hebert,R.Civitelli.Calcif Tissue Int 94:55-67(2014).

10. D.Wang ,P.S.Chang,Z.Wang,L.Sutherland,J.A.Richardson,E.Small,P.A.Krieg,E.N.Olson.Cell.Jun 29;105(7):851-62. (2001).

11. W.Xing, T.C.Zhang, D.Cao,Z.Wang, C.L.Antos, S.Li,Y.Wang, E.N.Olson, D.Z.Wang. CircRes. 2006 Apr 28;98(8):1089-97.

12. K.G.Shyu, W.P.Cheng, B.W.Wang. Mol Med. Jul 14;21:616-25.(2015).

13. J.M.Benns, R.I.Mahato, S.W.Kim.J. Control.Release.Feb.19;79(1-3):255-69. (2002).

14. C.H.Fry, G.P.Sui, N.J.Severs, C.Wu. Urology.Mar;63(3 Suppl 1):3-10. (2004).

15. L.Li, C.Jiang, P.Hao, W.Li, C.Song, B.Song.Am. J.Physiol.Cell.Physiol,293:C1627-C1635.(2007).

16. Y.Liao, C.P.Regan, I.Manabe, G.K.Owens, K.H.Day, D.N.Damon, B.R.Duling. Arterioscler Thromb Vasc Biol 27:1037-1042. (2007).

17. M.L.Rocha, A.H.Kihara, A.P.Davel, L.R.G.Britto, L.V.Rossoni, L.M.Bendhack. Cardiovasc Res 80:123-130. (2008).

18. M.Imamura, H.Negoro, A.Kanematsu, S.Yamamoto, Y.Kimur a, K.Nagane, T.Yamasaki, I.Kanatani, N.Ito,Y.Tabata,O.Ogawa. Am J Physiol Renal Physiol 297:F46-F54.(2009).

19. J.Chen, H.Yin, Y.L.Jiang, S.K.Radhakrishnan, Z.P.Huang, J.Li, Z.Shi, E.P.Kilsdonk, Y.Gui, D.Z.Wang, X.L.Zheng. Arterioscler.Thromb.Vasc.Biol 31:368-375.(2011).

20. D.Cao, C.Wang, R.Tang, H.Chen, Z.Zhang, M.Tatsuguchi, D.Z.Wang.J .Biol Chem. Nov 9;287(46):38495-504. (2012).

21. L.Raphel, A.Talasila,C.Cheung, S.Sinha.PLoS.One.7(8):e44052. (2012). 